\title{
Investigation of Thyroid Hormones and Prolactin Levels in Fertile and Infertile Women
}

\author{
Arzu Şahin ${ }^{1}$, Feyyaz Önder ${ }^{2}$ \\ ${ }^{1}$ Department of Physiology, Faculty of Medicine, Ordu University, Ordu, Turkey \\ ${ }^{2}$ Department of Physiology, Vocational School of Health Services, Mediterranean University, Antalya, Turkey
}

Received: 25 December 2015 accepted: 27 March 2016/ published online: 27 April 2016

(C) Ordu University Institute of Health Sciences, Turkey, 2016

\begin{abstract}
Objective: This study was conducted to investigate thyroid hormones and prolactin levels in fertile and infertile women.

Materials and Methods: The study enrolled a total of 84 women, 40 infertile and 44 fertile, aged between 15-45 years and applied to Kars Maternity and Child Hospital, Obstetrics Clinic and Artvin State Hospital, Obstetrics and Gynecology Clinic. The study population was divided into 3 groups: Group P ( $n=30$, women having primary infertility), Group $S$ ( $n=10$, women having secondary infertility) and Group $F(N=44$, fertile women). Blood samples were obtained in early follicular phase and serum thyrotropin (TSH), free triiodothyronine $\left(\mathrm{FT}_{3}\right.$ ), free thyroxine $\left(\mathrm{FT}_{4}\right)$ and prolactin levels were determined by Microparticle Enzyme Immunoasay (MEIA) method.

Results: Serum TSH levels were $1.70 \pm 0.40,1.60 \pm 0.20$ and $0.80 \pm 0.20 \mu \mathrm{IU} / \mathrm{ml}$ for the groups F, P and S, respectively ( $\mathrm{p}>0.05$ ). $\mathrm{FT}_{3}$ levels were $2.36 \pm 0.06,2.46 \pm 0.09$ and $2.35 \pm 0.2 \mathrm{pg} / \mathrm{ml}$ while $\mathrm{FT}_{4}$ levels were $0.98 \pm 0.02,0.94 \pm 0.04$ and $1.00 \pm 0.03 \mathrm{ng} / \mathrm{dl}$ for the groups $\mathrm{F}, \mathrm{P}$ and $\mathrm{S}$, respectively. There was a significant negative correlation between TSH and $\mathrm{FT}_{4}(\mathrm{p}=0.012, \mathrm{r}=-0.275)$ and a significant positive correlation between $\mathrm{FT}_{3}$ and $\mathrm{FT}_{4}(\mathrm{p}=0.002, \mathrm{r}=0.330)$. Serum prolactin levels were measured as $16.70 \pm 2.60,21.10 \pm$ 2.10 and $16.00 \pm 1.90 \mathrm{ng} / \mathrm{ml}$ respectively for the groups $\mathrm{F}, \mathrm{P}$ and $\mathrm{S}$ and no significant difference was detected between the groups with respect to prolactin levels ( $p>0.05)$.

Conclusion: As a result, there was no difference between the groups in terms of TSH, $\mathrm{FT}_{3}, \mathrm{FT}_{4}$ and prolactin levels. Hormone levels were generally within normal limits and therefore we determine no significant relationship between infertility and investigated parameters in this study.

Key words: $\mathrm{TSH}, \mathrm{FT}_{3}, \mathrm{FT}_{4}$, Prolactin, Infertility, Fertilty.

Address for correspondence/reprints:

Arzu Şahin

Telephone number: +90 $4522265214-5325$

E-mail: sahin-97@hotmail.com

DOI: $10.19127 / \mathrm{mbsjohs.88836}$

The study was presented as a poster at Joint Congress of Feps \& Turkish Society of Physiological Sciences, September 3-7

\section{Introduction}

Infertility is defined as failure to achieve pregnancy after at least one year of regular unprotected sexual intercourse of a couple at reproductive age (Vayena et al., 2002). Infertility despite regular unprotected sexual intercourse without any previous pregnancy is defined as primary infertility, whereas fertility problems following a previous experience of pregnancy is defined as secondary infertility (Unuane et al., 2011).
\end{abstract} 2011, Istanbul / Turkey 
Epidemiological data suggest that infertility affects $10-15 \%$ of couples at reproductive age (Vayena et al., 2002; Unuane et al., 2011). World Health Organization reported the causes of inferility of the couple arise from women in $37 \%$, from men in $8 \%$ and from both in $35 \%$ of the cases (Unuane et al., 2011).

As for the causes of female infertility, it is pointed out that ovulation disorders are held responsible in 25-32\%, tubal damage (Unuane et al., 2011; Thonneau et al., 1991) in 22-26\%, endometriosis in $15 \%$, hyperprolactinemia in $7 \%$ and various other reasons in $11 \%$ of the cases. Several studies have suggested that ovulation disorders cause more than half of female infertility (Unuane et al., 2011).

Treatment modality becomes apparent if the cause of infertility can be identified. The ovaries regularly communicate with the other endocrine organs. Therefore, it should be considered that any endocrine disorder in women can affect fertility at certain degrees (Boyar et al., 2013).

Hormonal disorders of the female reproductive system involve many problems originating from dysfunction of the hypothalamic-pituitary-ovarian axis. The problems caused by this axis are the most common disorders that often cause infertility (Doufas and Mastorakos, 2000; Williams et al., 2003). Prolactin, thyroid hormones and particularly thyroid stimulating hormone (TSH) are some of the crucial components considered in female infertility (Cramer et al., 2003). Various studies reported that hyperthyroidism can cause irregular cycles and increase the rate of miscarriage and premature birth in pregnant women especially in the first period of pregnancy, and also hypothyroidism has a considerably high correlation with menstrual disorders, an ovulatory cycles, decreased fertility and increased disease in pregnancy. Secretion of thyroid hormones should be at normal level for normal sexual functionality and regularity of the periods and sufficient fertility of the females (Doufas and Mastorakos, 2000; Poppe and Velkeniers, 2003; Poppe et al., 2007).

In addition, thyroid hormones change the sensitivity of the gonads to follicle stimulating hormone (FSH), luteinizing hormone (LH) and prolactin. Besides menstrual cycle disorders, hypothyroidism can also cause an increase particularly in the release of thyrotropin releasing hormone (TRH), which in turn increases the release of TSH and prolactin, eventually causing hyperprolactinemia, which is an important factor inhibiting the development of pregnancy. So, hypothyroidism should be taken into account in patients with hyperprolactinemia (Joshi et al., 1993; Krassas et al., 2010).

Infertility is among the major health problems when considered with its socio-cultural and economic dimensions. It is a multifactorial problem and thyroid hormone treatment can correct thyroid-related fertility problems.

This research was conducted to investigate serum thyroid hormones and prolactin levels in fertile and infertile women applied to Kars and Artvin State Hospitals and to determine any correlation between these hormones and fertility and infertility.

\section{Materials and Methods}

This study was carried out with a total of 84 married women, aged between 15-45 years and applied to Kars Maternity and Child Hospital Obstetrics Clinic and Artvin State Hospital Obstetrics and Gynecology Clinic in the period between November 2003 and June 2005. Patients were informed about the study and their names would remain confidential. Official approvals were also obtained from the relevant authorities. Patients were divided into 3 groups: fertility (uneventful pregnancy and childbearing ability) $(\mathrm{F} ; \mathrm{n}=44)$, primary infertility (inability to become pregnant within sexual maturity period) $(\mathrm{P} ; \mathrm{n}=30)$ and secondary infertility (inability to become pregnant again, despite a previous pregnancy) $(S ; n=10)$. Forms were prepared to obtain medical history of the patients. In the light of information obtained, some women were excluded from the study who suffered chronic hypertension, chronic kidney disease, chronic gastrointestinal disease, as well as those using drugs that can change the metabolism and hormonal balance. Consent was obtained from all patients to publish the study results, as required. Blood samples were taken from the antecubital vein between 08.30 and 10.30 a.m. in 2.-4. days of menstrual cycle of women kept calm with a view to eliminate possible confounding effects due to stress factors. Blood samples were centrifuged and sera were separated and kept in the freezer at $-35^{\circ} \mathrm{C}$ until analyzed. TSH, free triiodothyronine (FT3), free thyroxine (FT4) and prolactin (PRL) levels in the sera were determined using the Microparticle Enzyme Immunoassay (MEIA) method and commercial kits in the Biochemistry Laboratory of Artvin State Hospital. The reference values were taken as: $0.490-4.670 \mu \mathrm{IU} / \mathrm{ml}$ for TSH, $1.45-3.48$ 
$\mathrm{pg} / \mathrm{ml}$ for FT3, 0.71-1.85 pg/ml for FT4, and 1.39$25 \mathrm{ng} / \mathrm{ml}$ for PRL. The reference values of the Biochemistry Laboratory of Artvin State Hospital were used in the study.

In the statistical analyses, the mean values of the data $\operatorname{Av}(\mathrm{x})$ and standard errors $\mathrm{Sd}(\mathrm{x})$ were determined by using the statistical software package (Minitab). Analysis of variance (ANOVA) was used to compare three study groups. When statistically significant differences were determined in variance analysis, then Tukey's test was performed to specify the inter-group differences (Minitab, version 12.1, Pennsylvania, USA). $\mathrm{P}<0.05$ was considered as the statistically significant difference between the groups.

\section{Results}

The mean values and standard errors of the group data are presented in Table 1 . We observed higher prolactin levels in women with primary infertility, while lower TSH levels in women with secondary infertility in comparison to women in other groups, but these differences were not statistically significant. In addition, mutual correlations between the parameters obtained from the groups are given in Table 2 and the differences are highlighted by using * symbol.

Table 1. Mean values of the parameters in terms of the groups $\left(\bar{X}_{ \pm S} \bar{x}\right)$.

\begin{tabular}{llllll}
\hline Groups & $\begin{array}{l}\text { Age } \\
(\text { Year })\end{array}$ & $\begin{array}{l}\mathrm{FT}_{3} \\
(\mathrm{pg} / \mathrm{ml})\end{array}$ & $\begin{array}{l}\mathrm{FT}_{4} \\
(\mathrm{ng} / \mathrm{dL})\end{array}$ & $\begin{array}{l}\mathrm{TSH} \\
(\mu \mathrm{IU} / \mathrm{m})\end{array}$ & $\begin{array}{l}\text { Prolactin } \\
(\mathrm{ng} / \mathrm{ml})\end{array}$ \\
\hline $\begin{array}{l}\text { Fertile } \\
\text { Women } \\
(\mathrm{F} ; \mathrm{n}=44)\end{array}$ & $34.6 \pm 0.8$ & $2.36 \pm 0.06$ & $0.98 \pm 0.02$ & $1.7 \pm 0.4$ & $16.7 \pm 2.6$ \\
$\begin{array}{l}\text { Women } \\
\text { having }\end{array}$ & $29.3 \pm 1.3$ & $2.46 \pm 0.09$ & $0.94 \pm 0.04$ & $1.6 \pm 0.2$ & $21.1 \pm 2.1$ \\
$\begin{array}{l}\text { Primary } \\
\text { Infertility } \\
(\mathrm{P} ; \mathrm{n}=30)\end{array}$ & & & & & \\
$\begin{array}{l}\text { Women } \\
\begin{array}{l}\text { Having } \\
\text { Secondary }\end{array}\end{array}$ & $33.3 \pm 1$ & $2.35 \pm 0.2$ & $1.0 \pm 0.03$ & $0.8 \pm 0.2$ & $16 \pm 1.9$ \\
$\begin{array}{l}\text { Infertility } \\
(\mathrm{S} ; \mathrm{n}=10)\end{array}$ & & & & & \\
\hline
\end{tabular}

Table 2. Mutual correlations between the parameters

\begin{tabular}{|c|c|c|c|c|}
\hline & Age & $* \mathrm{FT}_{3}$ & $* \mathrm{FT}_{4}$ & Prolactin \\
\hline $\mathrm{FT}_{3}$ & $\begin{array}{l}r=-0.064 \\
P=0.567\end{array}$ & & & \\
\hline$* \mathrm{FT}_{4}$ & $\begin{array}{l}r=0.061 \\
P=0.583\end{array}$ & $\begin{array}{l}r=\mathbf{0 . 3 3 0} \\
\mathbf{p}=\mathbf{0 . 0 0 2}\end{array}$ & & \\
\hline Prolactin & $\begin{array}{l}r=-0.168 \\
P=0.127\end{array}$ & $\begin{array}{l}r \quad=- \\
0.009 \\
P=0.933\end{array}$ & $\begin{array}{l}r=0.128 \\
P=0.253\end{array}$ & \\
\hline *TSH & $\begin{array}{l}r=0.001 \\
P=0.993\end{array}$ & $\begin{array}{l}\mathrm{r} \quad= \\
0.148 \\
\mathrm{P}=0.183\end{array}$ & $\begin{array}{l}\mathbf{r}=- \\
0.275 \\
\mathbf{P}= \\
0.012\end{array}$ & $\begin{array}{l}r=0.073 \\
P=0.508\end{array}$ \\
\hline
\end{tabular}

Mean age was $32.60 \pm 0.69$ years of the married women aged between 15 and 45 years $(n=84)$. Considering the groups, mean age was found as $34.60 \pm 0.80$ years in the group $F \quad(n=44)$, $29.30 \pm 1.30$ years in the group $\mathrm{P}(\mathrm{n}=30)$, and $33.30 \pm 1.00$ years in the group $\mathrm{S}(\mathrm{n}=10)$. Mean age of the women having primary fertility was lower than those having secondary fertility, though it was not a statistically significant difference.

In this study, 19 of $44(43 \%)$ women in the group F, 11 of $30(36.6 \%)$ women in the group $\mathrm{P}$ and 4 of $10(40 \%)$ women in the group $S$ were found to be smokers, and there was no statistically significant difference between the groups with respect to smoking. The number of women who had abortion was $6(13.5 \%)$ in the group F, 10 $(33.3 \%)$ in the group P and $3(30 \%)$ in the group S, respectively.

Five (8.8\%) women of the group F, 9 (30\%) women of the group P and 2 (20\%) women of the group $\mathrm{S}$ reported menstrual cycle disorders. The number of women having abortion and menstrual cycle disorders were more in the infertility groups.

TSH levels were observed to be within normal limits in all groups. A negative correlation was detected between the mean values of TSH and FT4 levels in all groups $(\mathrm{p}=0.012, \mathrm{r}=-0.275)$ (Figure $1)$. 


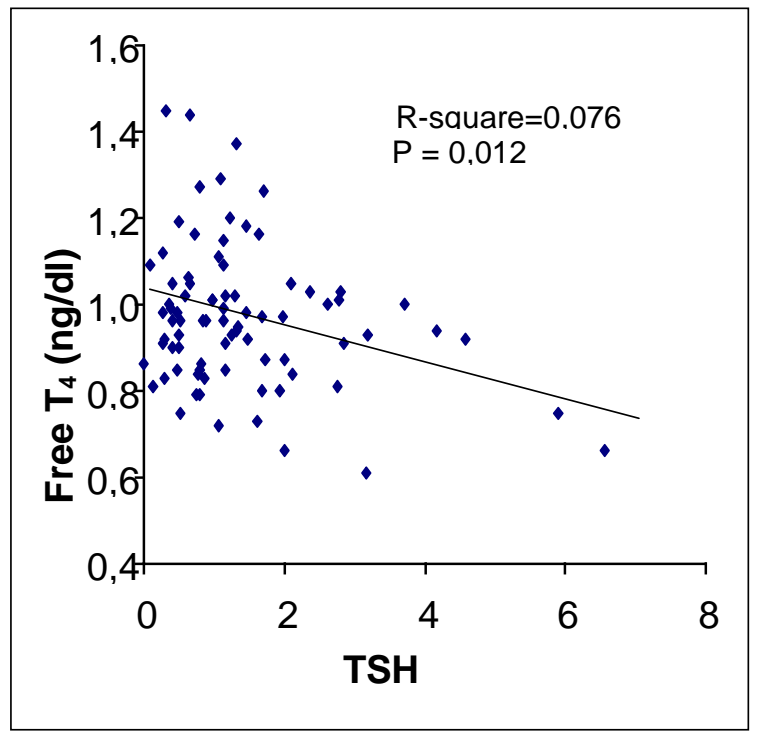

Figure 1. Correlation between FT4 and TSH levels.

Basal or even lower $(0.490-4.670 \mu \mathrm{IU} / \mathrm{ml}) \mathrm{TSH}$ levels were determined in $13.3 \%$ of group $\mathrm{P}$ and $20 \%$ of group S, out of those with menstrual cycle disorders. TSH values were below normal or very close to normal in $11 \%$ of the fertile women having menstrual cycle disorders, therefore statistically significant differences were not observed between the groups.

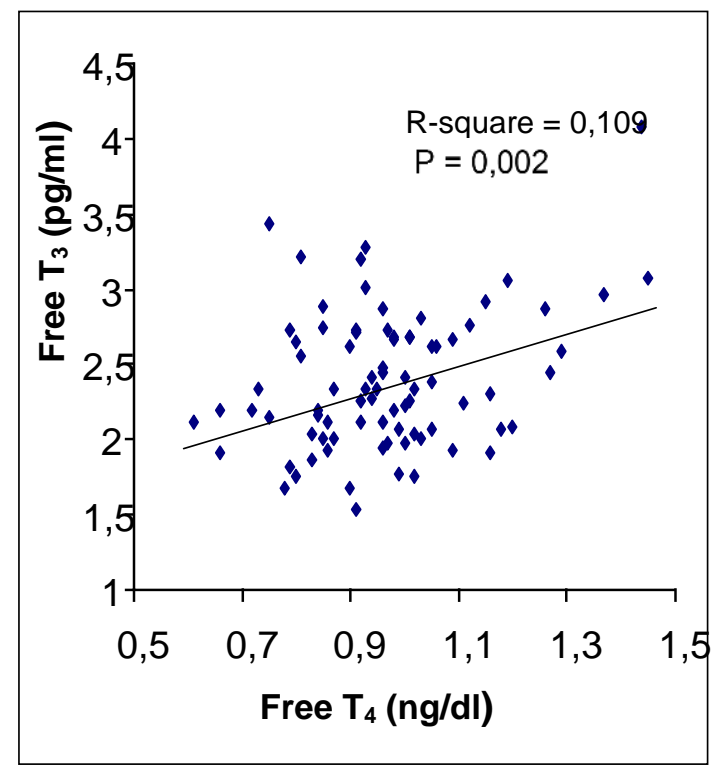

Figure 2. Correlation between $\mathrm{FT}_{4}$ and $\mathrm{FT}_{3}$ levels.
Mean prolactin, FT3 and FT4 values were within normal limits in all groups. A positive correlation was detected between FT3 and FT4 in the correlation analysis between the groups $(\mathrm{p}=0.002, \mathrm{r}=0.330)$ (Figure 2). Mean prolactin level was higher in the group $\mathrm{P}$ than the other groups, but the difference was not statistically significant $(\mathrm{p}=2.06)$.

\section{Discussion}

Thyroid hormones have very important impacts on reproduction and pregnancy. Various studies have reported broad-spectrum and significant influences of thyroid dysfunction such as reproduction abnormalities, abnormal sexual development, menstrual cycle irregularities and infertility (Bercovici, 2000; Vaquero et al., 2000; Davis et al., 2007).

The majority of the women in fertile and infertility groups displayed euthyroid state in terms of thyroid functions and they were within normal hormone levels.

In their study conducted with 119 infertile women, Bagis et al. (2001) reported mean age as 29.5 years in all women, as 28.6 in women with primary infertility and as 30.4 in women with secondary infertility. They pointed out higher mean age for the secondary infertility group than the other groups (Bagis et al., 2001). In our study too, mean age of the women with secondary infertility was significantly higher than those with primary infertility, and our results were in parallel with this study of Bagis et al., (2001); Menken et al., (1986) and Jaffe, (1991) reported reduced fertility with increasing age in women and indicated that 35-40 years of age was critical for becoming pregnant, which may be correlated with diseases such as endometriosis, anovulation and pelvic infection. In this study, since the mean age was found to be below 35 years, we speculate that infertility problems may be due to other factors rather than advanced age.

Elahi et al., (2007) reported no statistically significant difference in terms of thyroid dysfunction between fertile and infertile. On the other hand, Binita et al. (2009) although reported normal thyroid functions in majority of the infertile group and in the control group, they also pointed out that hypothyroid patients were considerably more in the infertile group than the control group. We determined no significant difference between the study groups in terms of FT3 and FT4, which may be attributed to euthyroid state of thyroid 
functions of vast majority of the subjects. Similar to our findings, Songur and Cetin (1996), Buyru et al,. (1996) and Shalev et al., (1994) also determined no statistically significant difference between control and infertile groups in terms of FT3 and FT4.

Turankar et al., (2013) reported increased levels of prolactin and TSH in infertile women compared to the control group.

In a similar study Sharma et al., (2012) investigated prolactin and TSH levels in primary and secondary infertile women and determined galactorrhea in $15 \%$ of the subjects. In addition, serum prolactin levels were measured as $79.40 \pm 56.59 \mathrm{ng} / \mathrm{mL}$ in hyperprolactinemic women; however, they reported no statistically significant difference in the levels of prolactin between the women with primary and secondary infertility.

We determined significantly higher prolactin levels in the women with primary infertility compared to the women in other two groups. No statistically significant difference was determined between the groups, in terms of prolactin levels. Similar to our findings, Buyru et al., (1996) reported high prolactin levels in only 2 of 340 infertile patients. Bagis et al., (2001) who conducted a similar study on 119 patients reported no hyperprolactinemia case. However, Lisa et al., (1988) suggested that a decrease in hypothalamic dopamine level may result in hyperprolactinemia. It should also be considered that in these patients, individual differences in response to stress factors when exposed to emotional or physical stress, as well as adenomas which are particularly detected in major endocrine glands such as pituitary gland or hypothalamus may also have a role in increased prolactin levels.

We found lower TSH levels in women with secondary infertility with respect to women in the other groups, which was not statistically significant. In addition, we found a positive correlation between FT3 and FT4 and a negative correlation between TSH and FT4. We determined no statistically significant differences between fertile and infertile groups in terms of TSH, which was compatible with some findings in the literature (Shalevet al., 1994; Buyru et al., 1996; Songur and Cetin, 1996).

\section{Conclusion}

As a result, except for some minor differences, we determined no statistically significant differences between groups in terms of TSH, FT3,
FT4 and prolactin. TSH levels may be important in menstrual cycle problems of fertile women, however, as for menstrual cycle problems in women with fertility problems, some other hormonal or physical disorders should also be considered besides TSH.

\section{Acknowledgement}

We sincerely thank Prof. Dr. Sedat YILDIZ for his help in evaluation and analysis of the statistical data and the staff of Artvin State Hospital and Kars Maternity and Child Hospital for their support in collecting the study data. This article is based on the Master Thesis titled "Determination of Thyroid Hormones and Prolactin Levels in fertile and infertile women ".

Informed Consent: Necessary information using the patient information form and consent form was taken from the patients.

Peer-review: Externally peer-reviewed.

Author Contributions: Concept- AS, FO, DesignAS, FO, Supervision-AS, FO, Funding- AS, FO, Materials- AS, FO, Data Collection and/or Processing- AS, FO, Analysis and/or Interpretation- SY, FO, Literature Review-, Writing- AS, FO, Critical Review- AS, FO

Conflict of Interest: No conflict of interest was declared by the authors.

Financial Disclosure: The authors declared that this study hasn't received any financial support.

\section{References}

Bagis T, Killıcadag E, Tarım E, Gokçel A, Haydardedeoglu B. Clinical evaluation of infertile patients. Turkish Fertile J 2001; 9(3): 215-25.

Bercovici JP. Menstrual irregularities and thyroid diseases. Feuill Biol 2000; 74: 1063-70.

Binita G, Suprava P, Mainak C, Koner BC, Alpana S. Correlation of prolactin and thyroid hormone concentration with menstrual patterns in infertile women. J Reprod Infertil 2009; 10(3): 207-12.

Boyar Hİ. Female infertility and endocrinological diseases. Dicle Med J 2013; 40(4): 700-3.

Buyru F, Serdaroglu H, Kovanci E, Baysal B. Thyroid dysfunction and infertility. Turkish Fertile J 1996; 4(1): 21-25. 
Cramer DW, Sluss PM, Powers RD, McShane P, Ginsburgs ES, Hornstein MD, et al. Serum prolactin and TSH in an in vitro fertilization population: is there a link between fertilization and thyroid function? J Assist Report Genet 2003; 20(6): 210-5.

Davis LB, Lathi RB, Dahan MH. The effect of infertility medication on thyroid function in hypothyroid women who conceive. Thyroid 2007; 17: 773-7.

Doufas AG, Mastorakos G. The hypothalamicpituitary-thyroid axis and the female reproductive system. Ann N Y Acad Sci 2000; 900: 65-76.

Elahi S, Tasneem A, Nazir I, Nagra SA, Hyder SW. Thyroid dysfunction in infertile women. Coll Physicians Surg Pak 2007; 17(4): 191-4.

Jaffe SB. The basic infertility investigation. Fertil Steril 1991; 61: 599.

Joshi JV, Bhandarkar SD, Chadha M, Balaiah D, Shah R. Menstrual irregularities and lactation failure may precede thyroid dysfunction or goitre. J Postgrad Med 1993; 39: 137-41.

Krassas GE, Poppe K, Glinoer D. Thyroid function and human reproductive health. Endocr Rev 2010; 31(5): 702-55.

Lisa H, Fish MD, Cary N. Hyperprolactinemia, infertility and hypothyroidism. Arch Intern Med 1988; 148: 709-11.

Menken J, Trussel J, Larsen U. Age and infertility. Sci 1986; 233: 1389-93.

Poppe K, Velkeniers B. Thyroid disorders in infertile women. Ann Endocrinol (Paris) 2003; 64 (1):45-50.

Poppe K, Velkeniers B, Glinoer D. Thyroid disease and female reproduction. Clin Endocrinol (Oxf) 2007; 66(3): 309-21.

Shalev E, Eliyahu S, Ziw M, Ben-Ami M. Routine thyroid function tests in infertile women : Are they necessary? Am J Obstet Gynecol 1994; 11 (91): 171.

Sharma N, Baliarsingh S, Kaushik GG. Biochemical association of hyperprolac-tinemia with hypothyroidism in infertile women. Clin Lab 2012; 58(7-8): 805-10.

Songur S, Cetin M. Ovulatory and anovulatory infertile women in routine thyroid function tests. Turkish Fertile Journal 1996; 4 (4): 355-7.

Thonneau P, Marchand S, Tallec A, et al. Incidence and main causes of infertility in a resident population of three French regions. Hum Reprod 1991; 6: 811-6.
Turankar S, Sonone K, Turankar A. Hyperprolactinaemia and IIts Comparision with Hypothyroidism in Primary Infertile Women. J Clin Diagn Res 2013; 7(5): 794-6.

Unuane D, Tournaye H, Velkeniers B, Poppe K. Endocrine disorders \& female infertility. Best Pract Res Clin Endocrinol Metab 2011; 25(6): 861-73.

Williams C, Giannopoulos T, Sherriff EA. Investigation of infertility with the emphasis on laboratory testing and with reference to radiological imaging. J Clin Pathol 2003; 56: 261-7.

Vaquero E, Lazzarin CD, Valensise H, Moretti C, Ramanini C. Mild thyroid abnormalities and recurrent spontaneous abortion: Diagnostic and therapeutic approach. Am J Reprod Immunol 2000; 43: 204-8.

Vayena E, Rowe P, Griffin P. Current Practices and Contro $\neg$ versies in Assisted Reprudiction. Report of a meeting on Medical, Ethical and Social Aspets of Assisted Reprodic $\neg$ tion held at WHO Headquarters; September, 17-21; Geneva - Switzerland: 2001. P.2002. 